\title{
Building the Measuring Stick: A Model for Continuous Review and Improvement of Institutional Repository Policies
}

\author{
Christy Shorey \\ University of Florida, USA
}

\begin{abstract}
The institutional repository at the University of Florida (IR@UF) was founded in 2006, and the policies have not been substantially reviewed or updated since that time. As the new institutional repository (IR) manager, I set out to create a list of current IR best practices and policies from peer institutions. Once collected, this list would serve as a guide to identify needed updates that would allow the IR@UF to best address the needs of the UF community within the current scholarly publishing environment.
\end{abstract}

The first step was a literature review to identify policies necessary for a thriving IR. I then compared current IR@UF policies, both public and internal, to identify where there were missing or weak policies. Evaluating the size of their IRs, years they were founded, and the types of objects collected, we identified 25 peer institutions. I did an environmental scan of these IRs by visiting their websites, searching for documentation of policies and practices.

With the help of our assessment librarian, Laura Spears, I created a Qualtrics survey, drawing from the environmental scan to craft focused questions about policies in four areas: administration, submissions, collections, and other (e.g., theses and dissertations, how related items are treated, etc.). I invited the 25 peer institutions to participate in the survey as a pilot; 15 replied. Using these results and feedback from peers, I updated the survey and sent it to a broader audience, yielding 94 domestic and international participants.

Some trends were easily identifiable, such as a majority of IRs being hosted on the DSpace or Digital Commons platforms, and spikes in creation of IRs in 2006, 2011, and 2015. Also present were general trends of how metadata was collected to describe items within the IR, and who set and maintained policies. Initial policies were developed mostly by advisory boards or a library department, while maintenance was primarily handled by a library department or an individual.

This qualitative analysis began as a way to measure the IR@UF policies and suggest policy revisions. The results of this research speak to broader implications. It is clear the state of institutional repositories within the scope of scholarly communication is currently under scrutiny, as evidenced by recent articles such as Clifford Lynch's 2017 article, "Updating the Agenda for Academic Libraries and Scholarly Communications," ${ }^{\text {and } ~ " T h e ~ E v o l v i n g ~ I n s t i t u t i o n a l ~ R e p o s i t o r y ~ L a n d s c a p e, ~ a ~ C h o i c e ~ W h i t e ~ P a p e r " ~ b y ~ J u d y ~}$ Luther, ${ }^{2}$ released earlier this year. Recent surveys of the current landscape of IRs look at topics from metadata collection to the creation and maintenance of IRs in Canada, as well as the use of Family Educational Rights and Privacy Act (FERPA) regulations for student works in IRs. Within this focus on IRs, understanding the policies of peer institutions is an important factor. My survey provides results from 94 participants, and serves as a case study other institutions can review based on their needs in comparison to peer institutions. The results of the survey also suggest further research opportunities into the relationship between IR platform and policies.

\section{Introduction}

Upon becoming manager of the institutional repository at the University of Florida (IR@UF), it became apparent to me that the corpus of related policies, procedures, and documentation had not undergone substantive review since its initial creation for the 2006 launch. Over the following decade, expectations for the role of institutional repositories (IRs) in general, and more specifically the needs of the UF community, shifted. Additionally, SobekCM, the platform used to host our institutional repository, changed and saw improvements as well as new challenges. In this fluctuating environment, the existing policies and 
procedures needed to be reviewed for current relevance and application. This process would serve as a guideline to establish a recurring review of the IR@UF policies, procedures, and documentation.

Starting with a list of questions about the role and limitations of the IR@UF that I had collected through both patron interactions and from my own experience with the IR@UF, I sought current resources that addressed best practices for IR policies and procedures. Although my research uncovered articles addressing the shifting role of institutional repositories and their relation to the Open Access movement, ${ }^{3}$ I was unable to find anything that specifically addressed either IR policies or procedures.

In the absence of current writings, I determined that, in order to compare IR@UF practices to the community best practices, I would have to reach out to the community to define those best practices. I began by creating a list of policies needed to support an institutional repository, from which I could then define best practices.

Instrumental in compiling my final list of policy requirements were "Documentation for institutional repositories, ${ }^{4}$ Starting, strengthening and managing institutional repositories, ${ }^{5}$ projects I wanted to undertake within the IR@UF, and requests I had received from the UF community in my role as IR manager. The resulting list of policies that should be in place can be found in Appendix A. Next, I reviewed all the local/internal documentation I could find regarding the creation of the IR@UF, as well as its policies, both public and internal, to identify missing or weak policies as compared to the list of policy guidelines.

\section{Process}

Once I had identified areas where the IR@UF policies needed further scrutiny and update, I began an environmental scan to determine what our peer institutions were doing with regard to IR policies.

\section{Identify Peers}

Library administration provided a list of other Association of Research Libraries (ARL) member institutions who had a similar ratio of library expenditures to university expenditures from their 2013 budget calculations. The list broke the institutions into three peer groups. Working with the director of digital production services, Chelsea Dinsmore, I started with all members from the group with the least deviation from our expenditure ratio and added three institutions from Group B. Next, we reviewed the ARL Institutional Repository Review for institutions that had similar founding dates, size, and collected object types as the IR@UF, bringing our final number up to 25 identified peer institutions (Appendix B).

\section{Environmental Scan}

Next, I created a series of questions I wanted answered about the policies and management of the institutional repositories at the peer institutions, based on the policy guidelines. The questions were broken up into four categories: administration (5), submissions (7), collections (4), and oOther policies (10). Using these questions, I reviewed the institutional repositories and related web pages at the identified institutions and recorded my results in a Microsoft Access database, including links to the main IR page, the name of the IR, and which platform the repository used.

\section{Follow Up with Targeted Questions}

Once the website scan was completed, I compiled the list of eight questions where fewer than five of the 25 institutions addressed the policy in question on their website. I emailed the questions to the primary contact for the 25 IRs, as identified in my website search. Fifteen institutions responded.

1. Who set(s) the policies for your institutional repository? Is it handled by an individual or a committee?

2. Are there any fees associated with posting any of the material into your institutional repository?

3. Are there minimum quality standards that must be met for submitted items? If so, what are they? 
4. Is material in your institutional repository ever weeded or checked for duplicates? How do you handle identified duplicates?

5. How do you handle items that are related? (E.g., link items; put items on the same record; create collections; etc.)

6. How do you handle materials that have been vetted through a different office (e.g., ETDs through the graduate school)? Does this impact policies on acceptance, changes to items, take-down, etc.? Does the vetting office have any say on items after they are submitted to the repository

If your institution hosts ETDs in your repository, I have two additional questions.

1. Do you host supplemental materials for ETDs? If so, how do these items refer back to the ETD? (Same or different way than question 5 above)

2. How full of a catalog record do you create for ETDs, and by what mechanism do you collect the metadata? (E.g., generated by person reviewing item, metadata self-submitted from student, metadata provided by graduate school, etc.)

\section{Build Survey}

Once I had collected and recorded the email responses, I worked with the assessment librarian, Laura Spears, to use the results of my website-based environmental scan to craft survey questions. Where I was able, I crafted control lists of responses to questions, which were informed by the results of the informal questions and the information gathered during my website search. Once we were happy with the wording, answer options, and question order, I created the survey in Qualtrics. Given my background with theses and dissertations, I included questions about ETDs under the "other policies" portion, as well as questions about metadata and collection clean-up.

\section{Survey to Peers}

After securing the IRB, I sent an invitation to the survey to representatives from the 25 peer institutions in April 2016. Fifteen completed the survey.

- Basic demographics (4 questions)

- Administration of the IR (4-5 questions)

- Submission process and policies (7 questions)

- IR collections (4 questions)

- Other IR policies, including policies surrounding metadata standards and ETDs (9-10 questions)

View the survey tool at: http://ufdc.ufl.edu/AA00039807/00001 (initial/pilot).

\section{Open Survey to Broader Group}

Based on feedback from peers, I expanded the question set by five questions, and clarified some questions where the initial replies indicated that doing so would facilitate more meaningful results. I sent out an invitation to the broader scholarly community to take the survey in October 2016. Overall, the survey had 94 participants from various domestic and international institutions.

- Basic demographics (6 questions)

- Administration of the IR (4-6 questions)

- Submission process and policies (7 questions)

- IR collections (4 questions)

- Other IR policies, including metadata standards and policies surrounding ETDs (9-12 questions)

View the survey tool at: http://ufdc.ufl.edu/AA00039807/00002 (revised/broader group). 


\section{Big Trends}

While institutions varied in responses across the survey, there were a few big trends that I was able to identify from the results. Looking at the demographics portion of the survey, these trends appear in the platforms used to host the IR and which unit at an institution handles the IR administration. The two most common platforms across the 68 respondents to the question were Digital Commons, with $47 \%$, and DSpace at $34 \%$. The next highest platform usage appeared under the "other, please describe" category, with Hydra and Hydra plus another system coming to $6 \%$ of the total. The remaining platforms each represented $1 \%$ of the responses. Since the survey, Elsevier acquired Digital Commons, a hosted service available through bepress. Anecdotally, this has led to some institutions migrating their IRs to other platforms. The full impact is yet to be determined, but I expect a shift in the distribution of platforms when the IR Policy Survey is reissued in 2019.

Figure 1: What platform/technology do you use for your IR?

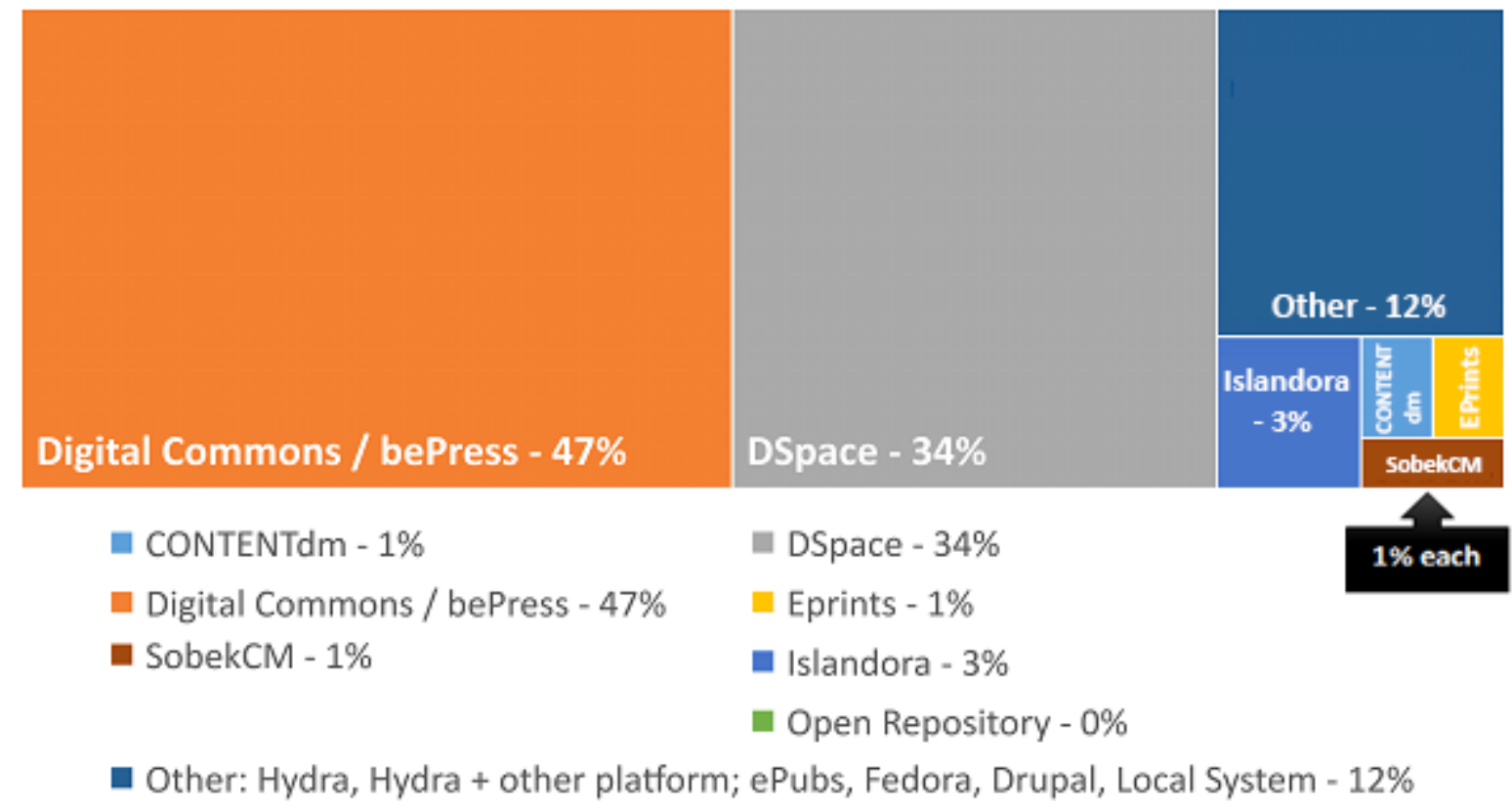

Sixty-eight participants responded to this demographics question. Two platforms, Digital Commons and DSpace, make up 81\% of responses. Responses from the 2016 issuance of the Institutional Repository Policy Survey.

One question where there was near uniform response was "Which department administers the IR at your institution?" The library administered the IR at all responding institutions, with $4 \%$ sharing administration with another department on campus.

Respondents also varied in which members from their community were allowed to submit items into their IR. Of the 65 institutions that responded to this question, $95 \%$ allow submissions from faculty members, $92 \%$ allow submissions from graduate students, and $83 \%$ allow submissions from staff. Other institutions also allow submissions from undergraduate students, emeritus faculty, and researchers affiliated with the institution, at $74 \%, 71 \%$, and $69 \%$ respectively.

In addition to looking at who could submit items for inclusion in the IR, I also asked whether institutions had a gatekeeper for materials loaded into the IR. Out of the 66 respondents, 12 institutions (11\%) did not have a gatekeeper, and approved individuals could load anything into the IR. In institutions where there is a gatekeeper, 52 (or $79 \%$ of respondents for this question) indicated that this role falls to "IR Manager / Repository Curator." 
Beyond policies addressing who manages the administrative functions of an IR, there are commonalities in terms of how institutions present the items within their collection. Sixty-four institutions responded to the question, "Please identify the distinct sub-collections contained in your IR (select all that apply)." The two most common sub-collections utilized by respondents were theses and dissertations at $88 \%$, and department-based collections (83\%). Community-based collections were utilized by $63 \%$ of respondents. Those institutions that were hosted on either DSpace or Digital Commons were more likely to have both community-based and department-based collections. This is just one example of possible future researchexploring whether the platform informs form, vice versa, or if no significant correlation exists between the two.

Figure 2: Sub-collections utilized by respondents' institutional repositories

\section{Please identify the distinct sub-collections contained in your IR}

\section{4 respondents}

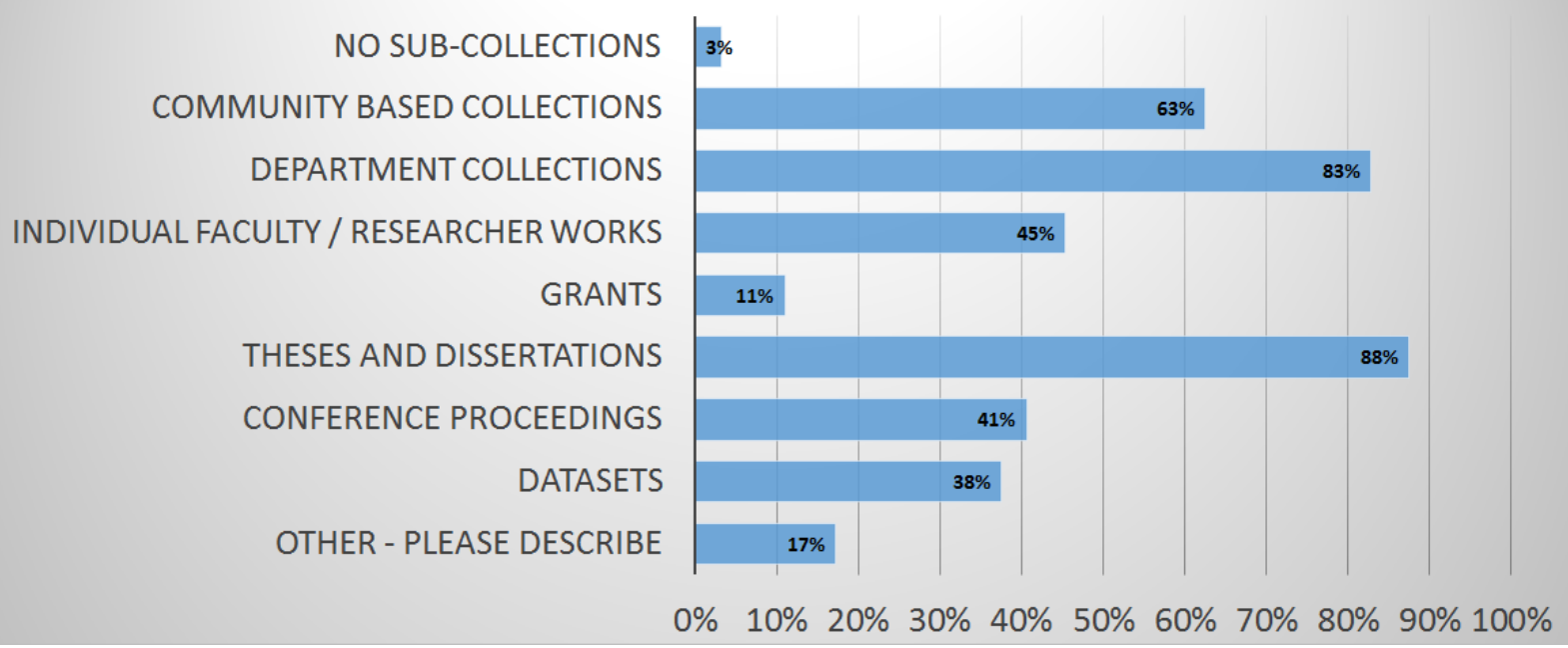

Sixty-four participants responded to this collection policy question. The most frequently utilized subcollections were "theses and dissertations," used by $88 \%$ of respondents, and "department collections," representing $83 \%$ of respondents.

Another area where I observed commonalities was in the collection of metadata to describe submitted works. This metadata could be collected from the submitter as either required, strongly preferred, or optional. Title, author, and date were most frequently identified as required. Abstract was most commonly a strongly preferred field, and examples of optional fields include citation, temporal coverage, and peer review status. Other metadata was most commonly added by staff, such as subject keywords, rights management statements, and type/format of the works. The complete dataset about metadata collection can be found in Appendix C. 
Figure 3: How metadata is collected, most common methods ${ }^{6}$

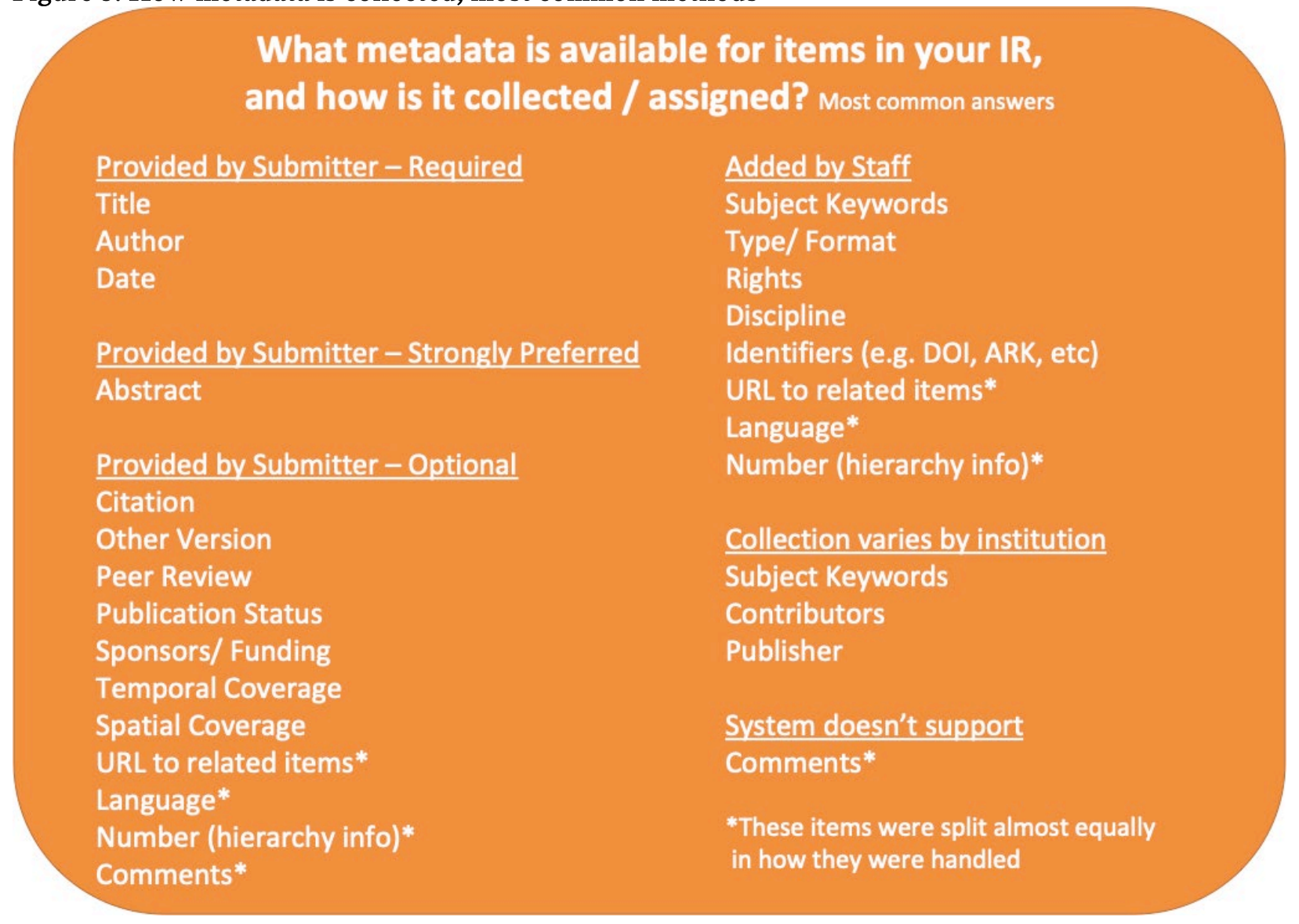

Results of the question addressing how metadata is collected for items submitted to the participants' institutional repositories. This box highlights the most common method of collection for the identified metadata fields. Each metadata field had between 59 and 64 respondents.

\section{Using survey results to update policies/procedures}

Using the survey results, I was able to identify best practices as defined by the most prevalent practices, though I do acknowledge that, simply because a method is most widely used, it is not necessarily the "best" practice, just the most common. Having a baseline of what other institutions were doing around policies and procedures, however, gave me something by which to measure our own. Not all of the identified best, or common, practices fit in with our institution's needs or platform, but understanding the trends has set us up for better positioning for possible future developments.

One key change in practices regarding the IR@UF is establishing a two-year review cycle for policies and procedures. This review is being set up along the guidelines of the Trustworthy Repositories Audit and Certification: Criteria and Checklist (TRAC) tool (http://www.crl.edu/archiving-preservation/digitalarchives/metrics-assessing-and-certifying/trac), which UF had already begun working with to evaluate our digital collections. Additionally, a regular review of registered users will be conducted to remove any individuals who are no longer associated with the University of Florida.

Another large change was to the structure of the IR@UF's collections and sub-collections. I reached out to our library liaisons to identify obsolete legacy collections that could be removed (many of which had a landing page, but contained no items). I also identified which liaison was the relevant subject specialist for each collection. This not only allowed us to provide a secondary contact for patrons, but also to bring the 
liaisons' knowledge of their fields to bear when considering future development and updates to these collections.

Collection of metadata was another area identified for improvement. Based on the trends (Appendix C), I am working with the metadata librarian and library IT to update our user self-submission form to include more metadata fields than the eight currently collected (only two of which are required), increasing the collected information to six required fields, five strongly encouraged fields, and at least two, but possibly up to eleven, optional fields. We are still weighing the pros and cons of including nine of the optional fields in the initial submission rather than as fields that can be updated after submission.

The only major policy that our previous policies did not address in any way was how to handle duplicate items loaded into the IR. Looking at the answers from our peers, I am writing this policy and accompanying workflow for implementation in 2019.

\section{Conclusion}

In a time when the scholarly community is looking closely at the role of institutional repositories within the broader scholarly communications environment, it is important for an institution to have touchstones to measure the relevance of their own institutional repository in this changing landscape. A major defining feature of institutional repositories are their policies and procedures surrounding what items are collected, who is able to submit items, and how submissions are handled throughout the submission process and beyond.

While current literature addresses the changes around the role of IRs since the early days of open access publishing, the only resources that look at policies for institutional repositories were dated. In the absence of a set of best practices for IR policies and procedures, I set out to create my own, based on the activities at peer institutions. The resulting survey helped identify common standards and practices which I have subsequently shared with the broader scholarly communications community (see Appendix D). Since this field experiences constant growth, so too should identification of best practices and conversations around the role of institutional repositories. With the creation of the IR Managers' Forum in early 2017, seeking respondents when the survey is reissued in 2019 should yield a broader variety and volume of respondents.

The results of the initial issuance of the IR Policy Survey not only have provided a road map for improvement of the policies and procedures for the IR@UF, but can also serve as a template for other institutions who are undertaking a similar policy review. While the survey identified some interesting trends, it also raised questions that could benefit from further research, such as an exploration of correlation between IR policies and platforms used to host institutional repositories, as well as a regular update of the survey so trends can be tracked over time.

-Copyright 2019 Christy Shorey 


\section{Endnotes}

1. Clifford Lynch, "Updating the Agenda for Academic Libraries and Scholarly Communications," College \& Research Libraries 78, no. 2 (April 2017): 126-130 https://doi.org/10.5860/crl.78.2.126.

2. Judy Luther, “The Evolving Institutional Repository Landscape," Copyright, Fair Use, Scholarly Communication, etc. no.70, https://digitalcommons.unl.edu/scholcom/70.

3. Lynch, "Updating the Agenda"; Richard Poynder, "Q\&A with CNI's Clifford Lynch: Time to Re-Think the Institutional Repository?" Open and Shut? (blog), September 22, 2016, http://poynder.blogspot.com/; Eric Van de Velde, "Let IR RIP," ScieTechSociety (blog), July 24, 2016, http://scitechsociety.blogspot.com/2016/07/let-ir-rip.html.

4. Steve Probets and Jenkins, Celia. "Documentation for institutional repositories." Learned Publishing Volume 19 Number 1 (January 2006): 57-71. https://doi.org/10.1087/095315106775122556.

5. Jonathan A. Nabe, Starting, strengthening and managing institutional repositories: a how-to-do-it-manual (New York: Neal-Schuman Publishers, 2010).

6. Nabe, Starting, strengthening and managing.

\section{Bibliography}

Luther, Judy, “The Evolving Institutional Repository Landscape.” Copyright, Fair Use, Scholarly Communication, etc. no.70. https://digitalcommons.unl.edu/scholcom/70.

Lynch, Clifford. "Updating the Agenda for Academic Libraries and Scholarly Communications.” College $\mathbb{E}$ Research Libraries 78, no. 2 (2017): 126-130. https://doi.org/10.5860/crl.78.2.126.

Nabe, Jonathan A. Starting, strengthening and managing institutional repositories: a how-to-do-it-manual. New York: Neal-Schuman Publishers, 2010.

Poynder, Richard. "Q\&A with CNI's Clifford Lynch: Time to re-think the institutional repository?" Open and Shut? (blog). September 22, 2016. http://poynder.blogspot.com/.

Probets, Steve and Jenkins, Celia. "Documentation for institutional repositories." Learned Publishing 19, no. 1 (January 2006): 57-71. https://doi.org/10.1087/095315106775122556.

Van de Velde, Eric. "Let IR RIP.” SciTechSociety (blog). July 24, 2016. http://scitechsociety.blogspot.com/2016/07/let-ir-rip.html. 


\section{Appendix A}

I. Probets Documentation

\section{A. Overview of IR/advocacy materials \\ B. Collections policy}

1. Withdrawal policy

2. Quality requirements

3. Status requirements

\section{Metadata}

1. Metadata schemes used

2. Level of metadata quality expected

3. Process of metadata creation

D. IR and Copyright (including $@$ guidance and deposit license)

1. Copyright guidance

2. Deposit License

a) Non-exclusive right to store and distribute authors' work

b) Non-exclusive right to make copies for backup and preservation

c) Legal rights and responsibilities of each of the stakeholders

d) Statement identifying (C) owner of resources in IR

e) Statement identifying $(\subset)$ owner of metadata in IR

E. Submission / deposit procedures

F. Details of submission workflows

G. Step-by-step instructions

H. Preservation policy

I. User policy

II. Nabe Book
A. Establishing communities and collections
B. Administering the IR communities 

C. Contributors
D. Content

1. Content types

2. File formats

3. Versioning

E. Use of content

F. Submission Agreements

G. Submission Process

H. Collections Policy
1. Withdrawal
2. Retention

I. Preservation Efforts

J. Additional considered
1. Fees for Space
2. Commercial Uses
3. Privacy
4. Quality Control

III. IR Plan Policies

A. Minimum metadata requirements

1. Include best practices/ lexicons for where available

B. Take down of items (user's request)

C. Content revision

1. Versioning

2. Update of materials

D. Embargos
1. Terminal projects
2. Other items 
E. Collections and keywords

1. Procedures on how to

2. Include best practices

F. Archiving materials

1. Self-submitted items

2. OJS journals

G. Mediated submissions

1. Harvesting (?)

H. Who can upload materials

1. Workflow for how permission granted

I. What is appropriate materials for IR

1. Link and metadata vs. item hosted in IR

2. If not, where it goes. Types to look at in particular
a) Library Training in IR
b) Other course material
c) Student organizations
d) Departmental materials, etc.
e) Use as portal (e.g. Hebblethwaite)

J. Copyright and rights statements

K. Works with multiple authors

L. Duplicate materials in IR

M. Sub-collections within IR 


\section{Appendix B}

Peer institutions as identified using a list of Association of Research Libraries (ARL) member institutions who had a similar ratio of library expenditures to university expenditures from their 2013 budget calculations. I started with all 11 members in the group with the least deviation from our expenditure ratio [1], and added three institutions from the next closest group [2]. Finally, we reviewed the ARL Institutional Repository Review for institutions that had similar founding dates, size, and collected object types as the IR@UF. We identified 11 additional institutions [3], bringing our final number up to 25 identified peer institutions (Appendix B).

- Columbia University [3]

- Cornell University [3]

- Duke University [3]

- Indiana University-Bloomington [1]

- Massachusetts Institute of Technology [3]

- Ohio State University [1]

- Penn State University [3]

- Purdue University [3]

- Southern Illinois University-Carbondale [3]

- Texas A\&M [1]

- University of Arizona [3]

- University of California at Berkeley [1]

- University of Illinois at Urbana-Champaign [1]

- University of Michigan-Ann Arbor [1]

- University of Minnesota [2]

- University of Nebraska-Lincoln [3]

- University of North Carolina at Chapel Hill [1]

- University of North Texas [3]

- University of Pittsburgh [2]

- University of Rochester [3]

- University of Texas at Austin [3]

- University of Utah [3]

- University of Virginia [1]

- University of Washington [2]

- University of Wisconsin-Madison [1] 
Appendix C

What metadata is available for items in your IR, and how is it collected / assigned? 64 respondents, with not all respondents answering all questions. Most common collection method appears in bold and italicized.

\begin{tabular}{|c|c|c|c|c|c|c|c|c|c|c|c|c|}
\hline $\begin{array}{l}\text { Metadata } \\
\text { Item }\end{array}$ & \multicolumn{2}{|c|}{$\begin{array}{l}\text { Required- } \\
\text { provided by } \\
\text { submitter }\end{array}$} & \multicolumn{2}{|c|}{$\begin{array}{l}\text { Preferred / } \\
\text { strongly } \\
\text { encouraged } \\
\text {-provided } \\
\text { by } \\
\text { submitter }\end{array}$} & \multicolumn{2}{|c|}{$\begin{array}{l}\text { Optional- } \\
\text { provided by } \\
\text { submitter }\end{array}$} & \multicolumn{2}{|c|}{$\begin{array}{l}\text { Assigned by } \\
\text { system }\end{array}$} & \multicolumn{2}{|c|}{$\begin{array}{l}\text { Added by } \\
\text { staff }\end{array}$} & \multicolumn{2}{|c|}{$\begin{array}{l}\text { System does } \\
\text { not support } \\
\text { / no place to } \\
\text { collect }\end{array}$} \\
\hline $\begin{array}{l}\text { Author / } \\
\text { Creator }\end{array}$ & $71.88 \%$ & 46 & $9.38 \%$ & 6 & $3.13 \%$ & 2 & $0.00 \%$ & 0 & $15.63 \%$ & 10 & $0.00 \%$ & 0 \\
\hline Title & $81.25 \%$ & 52 & $1.56 \%$ & 1 & $1.56 \%$ & 1 & $0.00 \%$ & 0 & $15.63 \%$ & 10 & $0.00 \%$ & 0 \\
\hline $\begin{array}{l}\text { Date (of this } \\
\text { version) }\end{array}$ & $56.25 \%$ & 36 & $17.19 \%$ & 11 & $1.56 \%$ & 1 & $4.69 \%$ & 3 & $20.31 \%$ & 13 & $0.00 \%$ & 0 \\
\hline Publisher & $12.90 \%$ & 8 & $22.58 \%$ & 14 & $29.03 \%$ & 18 & $3.23 \%$ & 2 & $32.26 \%$ & 20 & $0.00 \%$ & 0 \\
\hline Citation & $4.76 \%$ & 3 & $15.87 \%$ & 10 & $26.98 \%$ & 17 & $26.98 \%$ & 17 & $19.05 \%$ & 12 & $6.35 \%$ & 4 \\
\hline $\begin{array}{l}\text { URL to } \\
\text { related items }\end{array}$ & $3.17 \%$ & 2 & $11.11 \%$ & 7 & $39.68 \%$ & 25 & $1.59 \%$ & 1 & $38.10 \%$ & 24 & $6.35 \%$ & 4 \\
\hline $\begin{array}{l}\text { Other } \\
\text { location } \\
\text { (URL to } \\
\text { other online } \\
\text { location of } \\
\text { item) }\end{array}$ & $0.00 \%$ & 0 & $14.52 \%$ & 9 & $41.94 \%$ & 26 & $3.23 \%$ & 2 & $32.26 \%$ & 20 & $8.06 \%$ & 5 \\
\hline Other version & $0.00 \%$ & 0 & $8.33 \%$ & 5 & $46.67 \%$ & 28 & $3.33 \%$ & 2 & $26.67 \%$ & 16 & $15.00 \%$ & 9 \\
\hline $\begin{array}{l}\text { Identifiers } \\
\text { (e.g. DOI, } \\
\text { ARK, OCLC, } \\
\text { ISBN, ISSN, } \\
\text { URI, etc.) }\end{array}$ & $7.94 \%$ & 5 & $17.46 \%$ & 11 & $25.40 \%$ & 16 & $11.11 \%$ & 7 & $33.33 \%$ & 21 & $4.76 \%$ & 3 \\
\hline
\end{tabular}




\begin{tabular}{|c|c|c|c|c|c|c|c|c|c|c|c|c|}
\hline $\begin{array}{l}\text { Metadata } \\
\text { Item }\end{array}$ & \multicolumn{2}{|c|}{$\begin{array}{l}\text { Required- } \\
\text { provided by } \\
\text { submitter }\end{array}$} & \multicolumn{2}{|c|}{$\begin{array}{l}\text { Preferred / } \\
\text { strongly } \\
\text { encouraged } \\
\text {-provided } \\
\text { by } \\
\text { submitter }\end{array}$} & \multicolumn{2}{|c|}{$\begin{array}{l}\text { Optional- } \\
\text { provided by } \\
\text { submitter }\end{array}$} & \multicolumn{2}{|c|}{$\begin{array}{l}\text { Assigned by } \\
\text { system }\end{array}$} & \multicolumn{2}{|c|}{$\begin{array}{l}\text { Added by } \\
\text { staff }\end{array}$} & \multicolumn{2}{|c|}{$\begin{array}{l}\text { System does } \\
\text { not support } \\
\text { / no place to } \\
\text { collect }\end{array}$} \\
\hline Language & $4.76 \%$ & 3 & $12.70 \%$ & 8 & $28.57 \%$ & 18 & $11.11 \%$ & 7 & $28.57 \%$ & 18 & $14.29 \%$ & 9 \\
\hline $\begin{array}{l}\text { Type / } \\
\text { Format }\end{array}$ & $20.63 \%$ & 13 & $12.70 \%$ & 8 & $14.29 \%$ & 9 & $15.87 \%$ & 10 & $31.75 \%$ & 20 & $4.76 \%$ & 3 \\
\hline Peer Review & $1.67 \%$ & 1 & $11.67 \%$ & 7 & $30.00 \%$ & 18 & $5.00 \%$ & 3 & $25.00 \%$ & 15 & $26.67 \%$ & 16 \\
\hline Comments & $0.00 \%$ & 0 & $1.61 \%$ & 1 & $33.87 \%$ & 21 & $1.61 \%$ & 1 & $25.81 \%$ & 16 & $37.10 \%$ & 23 \\
\hline Abstract & $12.70 \%$ & 8 & $42.86 \%$ & 27 & $20.63 \%$ & 13 & $0.00 \%$ & 0 & $23.81 \%$ & 15 & $0.00 \%$ & 0 \\
\hline $\begin{array}{l}\text { Publication } \\
\text { status }\end{array}$ & $6.56 \%$ & 4 & $19.67 \%$ & 12 & $32.79 \%$ & 20 & $3.28 \%$ & 2 & $26.23 \%$ & 16 & $11.48 \%$ & 7 \\
\hline $\begin{array}{l}\text { Subject } \\
\text { keywords }\end{array}$ & $12.90 \%$ & 8 & $27.42 \%$ & 17 & $27.42 \%$ & 17 & $0.00 \%$ & 0 & $30.65 \%$ & 19 & $1.61 \%$ & 1 \\
\hline Discipline & $14.29 \%$ & 9 & $12.70 \%$ & 8 & $23.81 \%$ & 15 & $4.76 \%$ & 3 & $34.92 \%$ & 22 & $9.52 \%$ & 6 \\
\hline $\begin{array}{l}\text { Series / } \\
\text { Number } \\
\text { (hierarchy } \\
\text { info) }\end{array}$ & $1.69 \%$ & 1 & $11.86 \%$ & 7 & $32.20 \%$ & 19 & $8.47 \%$ & 5 & $32.20 \%$ & 19 & $13.56 \%$ & 8 \\
\hline $\begin{array}{l}\text { Sponsors / } \\
\text { Funding }\end{array}$ & $1.61 \%$ & 1 & $16.13 \%$ & 10 & $45.16 \%$ & 28 & $0.00 \%$ & 0 & $16.13 \%$ & 10 & $20.97 \%$ & 13 \\
\hline Rights & $20.63 \%$ & 13 & $12.70 \%$ & 8 & $17.46 \%$ & 11 & $4.76 \%$ & 3 & $36.51 \%$ & 23 & $7.94 \%$ & 5 \\
\hline Contributors & $9.84 \%$ & 6 & $27.87 \%$ & 17 & $24.59 \%$ & 15 & $0.00 \%$ & 0 & $29.51 \%$ & 18 & $8.20 \%$ & 5 \\
\hline $\begin{array}{l}\text { Temporal } \\
\text { coverage }\end{array}$ & $3.28 \%$ & 2 & $4.92 \%$ & 3 & $47.54 \%$ & 29 & $0.00 \%$ & 0 & $11.48 \%$ & 7 & $32.79 \%$ & 20 \\
\hline
\end{tabular}




\begin{tabular}{|l|l|l|l|l|l|l|l|l|l|l|l|l|}
\hline $\begin{array}{l}\text { Metadata } \\
\text { Item }\end{array}$ & $\begin{array}{l}\text { Required- } \\
\text { provided by } \\
\text { submitter }\end{array}$ & $\begin{array}{l}\text { Preferred / } \\
\text { strongly } \\
\text { encouraged } \\
\text {-provided } \\
\text { by } \\
\text { submitter }\end{array}$ & $\begin{array}{l}\text { Optional- } \\
\text { provided by } \\
\text { submitter }\end{array}$ & $\begin{array}{l}\text { Assigned by } \\
\text { system }\end{array}$ & \multicolumn{2}{|l|}{$\begin{array}{l}\text { Added by } \\
\text { staff }\end{array}$} & \multicolumn{2}{|l}{$\begin{array}{l}\text { System does } \\
\text { not support } \\
\text { /no place to } \\
\text { collect }\end{array}$} \\
\hline $\begin{array}{l}\text { Spatial } \\
\text { coverage }\end{array}$ & $1.64 \%$ & 1 & $3.28 \%$ & 2 & $42.62 \%$ & 26 & $0.00 \%$ & 0 & $18.03 \%$ & 11 & $34.43 \%$ & 21 \\
\hline
\end{tabular}




\section{Appendix D}

Previous works I created to disseminate information about the IR policy pilot and full survey process and results.

"Mapping the Landscape of ETDs and IRs: Results from the Institutional Repository Policy Survey." Refereed poster with G.W. Swicord for the $20^{\text {th }}$ annual International Symposium on Electronic Thesis and Dissertation, Washington, DC, Aug. 8, 2017 (http://ufdc.ufl.edu/IR00010029/00001).

"Identifying Policy Trends: Institutional Repository Policy Survey Results.” Refereed poster for the Southern Mississippi Institutional Repository Conference (SMIRC), Apr. 12, 2017 (http://ufdc.ufl.edu/l/IR00009690/00001).

"There's a Policy for That? Results from an informal survey of institutional repository practices." Refereed poster for the American Library Association (ALA) 2016 annual conference 2016, Orlando, FL, June 25, 2016, (http://ufdc.ufl.edu/IR00007436/00001).

"There's a policy for that? Results from an informal survey of IR practices." Refereed presentation for Institutional Repository (IR) Day at University of Southern Mississippi, Hattiesburg, MS, Apr. 28, 2016 (http://ufdc.ufl.edu/IR00007430/00001). 